\title{
Estudo da adição de resíduo (lodo) de gemas na massa cerâmica vermelha
}

\section{(Study of the gem residue (sludge) addition in bulk red ceramics)}

\author{
F. R. Bruxel, E. C. Oliveira, S. Stulp, C. S. Muller, H. D. Etchepare \\ Univates - Centro Universitário, Rua Avelino Tallini 171, Lajeado, RS \\ eniz@univates.br
}

\begin{abstract}
Resumo
Este trabalho tem como objetivo incorporar resíduo de gemas (lodo da serra de corte das gemas), produzido em uma empresa de lapidação de ametistas e ágatas, à massa cerâmica vermelha utilizada para a produção de tijolos maciços. As matérias-primas foram submetidas a ensaios de fluorescência de raios X, difração de raios X e análise granulométrica, para caracterização mineralógica e físico-química. Foram preparados corpos de prova com $0 \%, 5 \%, 9 \%, 13 \%$ e $17 \%$ de resíduo adicionado à massa cerâmica, em massa. As propriedades físicas estudadas foram a resistência à compressão, a retração linear, a absorção de água e a massa específica, de acordo com norma técnica vigente. Os resultados mostraram que é possível incorporar até 5\% de resíduo na massa cerâmica. Palavras-chave: resíduo, lodo de gemas, cerâmica vermelha.
\end{abstract}

\begin{abstract}
This work aims to incorporate gems waste (sludge saw cutting of gems), produced in an amethyst and agate firm cut, in the red ceramic body used for the production of solid bricks. The raw materials were tested by X-ray fluorescence, X-ray diffraction and granulometric distribution analysis, for characterize the mineralogy and physical chemistry of materials. Samples were prepared with $0 \%, 5 \%, 9 \%, 13 \%$ and $17 \%$ waste added to the ceramic body by mass. The physical properties studied were compressive strength, linear shrinkage, water absorption and density in accordance with current technical standard. The results showed that it is possible to incorporate up to $5 \%$ of waste in bulk ceramics.
\end{abstract}

Keywords: waste, gems sludge, red ceramic.

\section{INTRODUÇÃO}

Nos últimos anos, têm sido realizados vários trabalhos envolvendo reciclagem de resíduos industriais com sucesso, embora este tema não faça parte da cultura dos empresários e cidadãos brasileiros, como deveria. Podem-se citar três como as principais razões, para que países do Norte busquem a reciclagem de seus rejeitos industriais: o esgotamento das reservas de matérias-primas confiáveis; o elevado volume de resíduos sólidos, que põem em risco a saúde pública e a necessidade de compensar o desequilíbrio devido às variações no preço do petróleo [1]. Atualmente, o uso de resíduos para a produção de produtos cerâmicos tornou-se uma alternativa, muitos trabalhos têm sido reportados na literatura onde são incorporados resíduos à massa cerâmica vermelha, tais como, lama de mármore e granito [2-4], lodo de indústria de papel reciclado [5], lodo de estação de tratamento de água (ETA) [6, 7], escória de chumbo [8], resíduo oleoso do setor petrolífero [9], chamote proveniente de refugo de tijolos [10] lama de alto forno de indústria siderúrgica integrada [11], cinza de lenha [12], lama fina de aciaria [13], dentre outros. Os materiais utilizados pela indústria cerâmica são geralmente com características heterogêneas, constituídos por materiais plásticos e não plásticos, o que permite a incorporação de vários tipos de resíduos, com percentagens bastante significativas [1].

Materiais gemológicos naturais são aqueles formados inteiramente pela natureza, sem interferência do homem, podendo ser de origem inorgânica (minerais e rochas) ou orgânica (animal ou vegetal). Chamam-se de gemas naturais, as substâncias naturais orgânicas ou inorgânicas, que por suas propriedades físicas características (cor, brilho, raridade, dureza) são utilizadas principalmente como adorno pessoal [14]. O Estado do Rio Grande do Sul concentra as maiores jazidas mundial de ágata e ametista, possuindo um parque industrial de lapidação e joalheria, integrado por cerca de 600 empresas de pequeno porte. As principais jazidas exploradas encontram-se, principalmente, ao norte, na região do Médio Alto Uruguai, e ao sudoeste, na região da Fronteira Oeste, de onde é extraída a ametista. No centro do Estado, compreendendo a região do Alto Jacuí, ocorre a extração de ágatas. Além da ametista e da ágata, ainda existem no Estado ocorrências de quartzo (cristal-de-rocha, quartzo rosa, quartzo leitoso), calcita, apofilita, zeolita, gipsita, calcedônia, ônix, jaspe e opala. Em Lajeado, assim como em outras cidades do Vale do Taquari, existem cerca de 250 microempresas e pequenas empresas que operam no segmento de lapidação, artefatos de gemas, máquinas 
e equipamentos. Soledade caracteriza-se como principal centro de comercialização de gemas do Estado. As jazidas de ametista, citrino e ágata são encontradas em toda a extensão do derrame geológico do Estado, que se estende de Santana do Livramento até Ametista do Sul, com ramificações por São Martinho da Serra e em vários pontos da Serra Gaúcha [15].

Produtos oriundos da argila ou misturas contendo argila, através da moldagem, secagem e queima (origem da cor avermelhada), são chamados de cerâmica vermelha, tais como tijolos, blocos e telhas [16], sendo os tijolos objeto deste estudo. Foram avaliadas 1.689 indústrias de cerâmica vermelha no Rio Grande do Sul, concluindo que o setor é conservador com relação aos seus produtos, sistema produtivo e tecnologia utilizada, formado principalmente de pequenas e médias empresas [17]. Em nível de Brasil a indústria de cerâmica vermelha pulveriza-se por todo o país como microempresas e pequenas empresas, geralmente de organização simples e familiar [18]. Outro estudo realizado com 795 indústrias cerâmicas do Estado do Rio Grande do Sul cadastradas e não cadastradas no SINDICER-RS (Sindicato das Indústrias de Olaria e de Cerâmica para Construção no Estado do Rio Grande do Sul), verificou que $77,5 \%$ da matéria-prima utilizada vêm de jazidas próprias e que $90 \%$ não realizam análise física dos componentes da argila. As empresas pesquisadas têm como principal atividade a fabricação de artefatos em cerâmica ou barro cozido para uso na construção civil. A maior concentração de indústrias está localizada nos Vales do Caí e do Taquari e as demais estão distribuídas nas regiões Noroeste, Serra, Sul e Campanha [19]. Em razão da existência no Vale do Taquari de diversas empresas beneficiadoras de gemas, geradoras de resíduos, e da concentração de indústrias cerâmicas nesta mesma região, este trabalho tem por objetivo avaliar a adição de resíduos provenientes da serra de corte de gemas, principalmente ágatas e ametistas, à massa cerâmica vermelha utilizada na produção de blocos de tijolos maciços.

\section{MATERIAIS E MÉTODOS}

Foram coletados dois materiais, argila e lodo proveniente da serra do corte de indústria de gemas. A argila foi fornecida pela empresa Cerâmica Bruxel Ltda., de Arroio do Meio, RS, sendo a jazida de extração da argila localizada no mesmo município. O lodo de gemas foi fornecido pela empresa Caye Pedras Brasil de Teutônia, RS. No lodo também há óleo diesel marítimo, usado para lubrificar a serra de corte. As gemas são oriundas de jazidas localizadas no município de Salto do Jacuí e Ametista do Sul, RS, e do município de Artigas, Uruguai. Ainda cabe destacar que segundo norma de classificação de resíduos sólidos [20] o resíduo de gemas é classificado como resíduo de mineral não-metálico, e, portanto classificado como não perigoso, exceto pela presença de óleo, sendo que este é classificado como resíduo perigoso de fonte não específica, de periculosidade tóxica, estando em pequenas concentrações no lodo avaliado, pelo fato de haver recuperação do óleo para posterior reutilização pela empresa, no processo de beneficiamento de gemas.

Após a coleta os materiais (argila e lodo) foram secos em estufa a $110{ }^{\circ} \mathrm{C}$ e desagregados manualmente e peneirados $(0,84 \mathrm{~mm})$. A composição química foi determinada por fluorescência de raios X em equipamento Philips P2400 $\mathrm{X}$ 'Pert. A espectrometria de fluorescência de raios $\mathrm{X}$ foi usada para determinar os óxidos na argila e no lodo de serra. Espectrometria de absorção atômica (EAA Spectrometer Solar Unicam 969) foi realizada para a análise de vanádio. Os percentuais dos óxidos foram avaliados em base calcinada a $100{ }^{\circ} \mathrm{C}$. A composição mineralógica foi obtida por difração de raios X em equipamento Philips X'Pert Pro PW 3040/00, com radiação de cobre operando a $40 \mathrm{kV}$ e $40 \mathrm{~mA}$, com $2 \theta$ variando entre $5^{\circ}$ a $75^{\circ}$, passo $0,02^{\circ}$ e tempo de contagem de $5 \mathrm{~s} /$ passo. A granulometria dos materiais foi determinada por peneiramento e sedimentação de acordo com norma técnica [21].

Foram produzidos 550 corpos de prova, com forma de paralelepípedo-retângulo, com dimensões $10,5 \mathrm{~cm} \times 5,5$ $\mathrm{cm} \times 22,5 \mathrm{~cm}$ [22], com cinco composições, misturando a argila cerâmica com o lodo de serra de gemas. Os materiais foram misturados em uma betoneira; após, esta mistura foi acondicionada em uma esteira transportadora e conduzida até a maromba industrial. As cinco composições utilizadas foram: $100 \%$ de massa cerâmica e as demais composições de argila com $5 \%(\mathrm{~m} / \mathrm{m}), 9 \%(\mathrm{~m} / \mathrm{m}), 13 \%(\mathrm{~m} / \mathrm{m})$ e $17 \%(\mathrm{~m} / \mathrm{m})$ de lodo de serra adicionado, denominados T0, T5, T9, T13 e $\mathrm{T} 17$, respectivamente [23]. Os corpos de prova produzidos com as diferentes composições foram levados ao secador industrial, sendo processados de 30 a $90{ }^{\circ} \mathrm{C}$. O processo de secagem é necessário para a retirada da maior quantidade de umidade possível de dentro da massa dos tijolos. Depois da secagem, os corpos de prova foram queimados em forno túnel de 800 a $850{ }^{\circ} \mathrm{C}$ (cozedura). Completando a queima, os tijolos foram resfriados em temperatura ambiente. Após o processo de cozedura, foram feitas as análises físicas dos corpos de prova, em suas diferentes composições. Utilizou-se como parâmetros de avaliação nas diferentes composições, propriedades físicas e mecânicas, ou seja, a resistência à compressão, a retração linear, absorção de água [22, 24, 25] e, além destas, foram determinadas a homogeneidade, por microscopia, e massa específica. Todas as análises foram feitas em triplicata. Os testes de resistência à compressão foram em uma prensa Solotest com curso máximo $30 \mathrm{~mm}$, com indicador digital e bomba Emerson B e com 10.000 psi de capacidade máxima. A absorção de água foi em balança de precisão Bel Eng. M1702 e estufa Biopar. Para os testes de retração linear utilizou-se um paquímetro Universal 300 mm Starrett. A massa específica aparente foi determinada pelo método de Arquimedes em água, em balança Bel Mark 210A com kit hidrostático. As micrografias foram obtidas em um microscópio óptico binocular Quimis Q730MIT (aumento de até 1000x).

\section{RESULTADOS E DISCUSSÃO}

A Tabela I apresenta a composição química da argila 
Tabela I - Composição química da argila e do resíduo.

[Table I - Clay and waste chemical compositions.]

\begin{tabular}{lccccccccccc}
\hline Amostras & \multicolumn{110}{c}{ Composição em massa (\%) } \\
\hline & $\mathrm{Al}_{2} \mathrm{O}_{3}$ & $\mathrm{CaO}$ & $\mathrm{Fe}_{2} \mathrm{O}_{3}$ & $\mathrm{~K}_{2} \mathrm{O}$ & $\mathrm{MgO}$ & $\mathrm{MnO}$ & $\mathrm{Na}_{2} \mathrm{O}$ & $\mathrm{P}_{2} \mathrm{O}_{5}$ & $\mathrm{SiO}_{2}$ & $\mathrm{TiO}_{2}$ & $\mathrm{PF}^{*}$ \\
Argila & 15,13 & 0,98 & 12,15 & 1,52 & 0,78 & 0,25 & 0,75 & 0,23 & 58,96 & 1,86 & 7,4 \\
Resíduo & 0,25 & 0,45 & 0,64 & $<0,01$ & 0,22 & 0,01 & 0,08 & $<0,01$ & 94,77 & 0,04 & 3,53 \\
\hline \multicolumn{2}{l}{ *Perda ao Fogo }
\end{tabular}

e resíduo utilizado. A composição química na amostra de argila está de acordo com o que a maior parte das argilas tem apresentado [2], ou seja, é rica em sílica (59\%) e alumina $(15,1 \%)$, apresentando quantidades menores de óxidos de $\mathrm{K}, \mathrm{Mg}, \mathrm{Mn}, \mathrm{Na}$ e Ti. A elevada quantidade de sílica indica a provável presença de argilominerais tais como caulita $\left(\mathrm{Al}_{2} \mathrm{Si}_{2} \mathrm{O}_{5}(\mathrm{OH})_{4}\right)$ e muscovita $\left(\mathrm{KAl}_{2} \mathrm{Si}_{3} \mathrm{AlO}_{10}(\mathrm{OH}, \mathrm{F})_{2}\right)$, bem como quartzo livre. O que pode ser destacado é a presença considerável de óxido de ferro $(12,1 \%)$, que é responsável pela coloração avermelhada nos produtos após sua queima $[3,26]$. A perda ao fogo $(7,4 \%)$ da argila está relacionada com a perda de voláteis, queima de material orgânico, decomposição de carbonatos, perda de água e desidratação de hidróxidos [2, 3]; porém este valor relativamente baixo confirma o elevado percentual de $\mathrm{SiO}_{2}$. A perda ao fogo $(3,5 \%)$ do resíduo deve-se provavelmente à combustão do óleo mineral adicionado como lubrificante e à presença de carbonatos de cálcio (aragonita) e magnésio. A composição química do resíduo com $94,8 \%$ de sílica mostra a presença da ágata e ametista no resíduo.

A Fig. 1 apresenta os difratogramas de raios $\mathrm{X}$ da argila, do resíduo e do tijolo com $5 \%$ de resíduo. A argila é

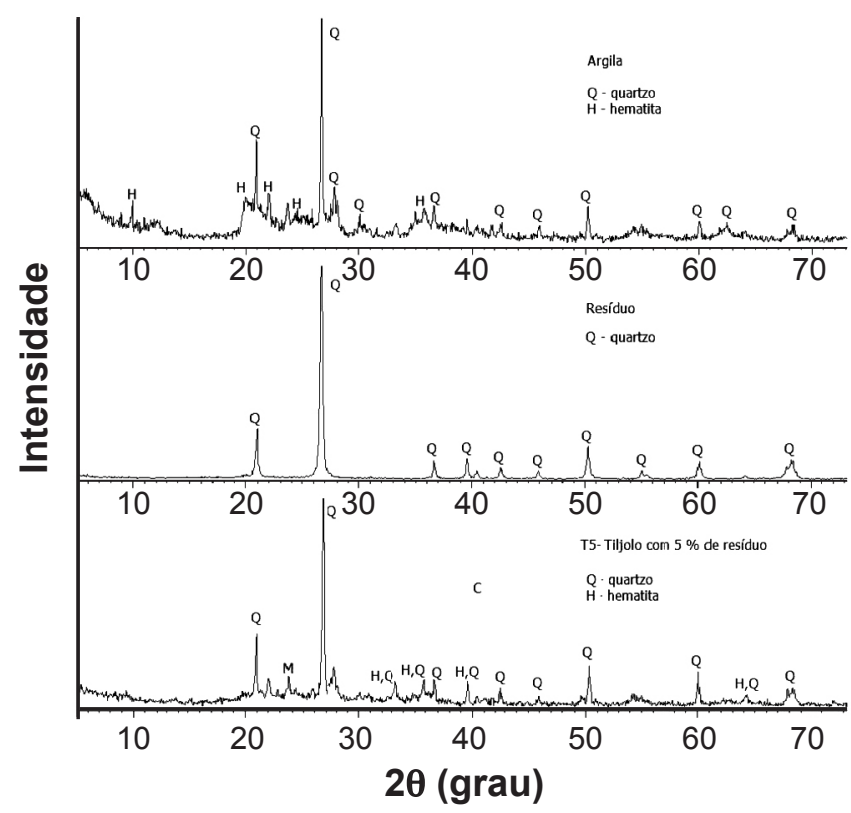

Figura 1: Difratogramas de raios $\mathrm{X}$ da argila, resíduo e tijolo (T5).

[Figure 1: X-ray diffraction patterns of clay, waste and brick (T5).] constituída de quartzo e hematita, que confere a coloração vermelha à massa cerâmica. No resíduo há predominância do quartzo, que é o principal componente da ágata e ametista. Já o tijolo com $5 \%$ de resíduo (T5) contém basicamente quartzo e hematita.

$\mathrm{Na}$ Tabela II tem-se a análise granulométrica da argila bruta; trata-se de um material de característica coesa, contendo majoritariamente fração argila e silte $(65 \%)$, que são extremamente importantes para um processo de queima adequado, sem trincas [27]. Partículas com tamanho elevado causam problemas na etapa de queima do tijolo provocando trincas devido à transformação alotrópica do quartzo, que ocorre com redução de volume [26].

A Tabela III apresenta os resultados das análises de resistência à compressão, massa específica, retração linear e absorção de água para os corpos de prova com diferentes quantidades de resíduos incorporados a massa cerâmica.

Conforme as normas técnicas [22], os tijolos maciços são classificados, dependendo da resistência que atingirem, em categoria A (1,5 MPa), B (2,5 MPa) e C (4,0 MPa). Sendo assim, pode-se verificar na Tabela II que os tijolos T0, T5, T9 e T17, analisados no teste de resistência à compressão, estão acima do mínimo exigido pela referida norma. Ressaltando que, à medida que aumenta a porcentagem de lodo de serra (resíduo) incorporado na massa cerâmica, diminui o grau de resistência dos tijolos. A absorção de água (Tabela III) aumenta conforme aumenta a quantidade de resíduo incorporado na massa cerâmica. Lama de mármore e granito foram incorporadas em massas argilosas e foi observado que para a mesma temperatura de queima, a absorção de água aumenta com o aumento da incorporação do resíduo [2]. Os valores obtidos para os corpos de prova (T5, T9, T13 e T17) foram superiores ao permitido pela norma técnica relativa à absorção de água (20\%). A Fig. 2 apresenta a retração linear para os corpos de prova com as diferentes composições do tijolo verde ao queimado.

Há uma diminuição na retração linear com o aumento do percentual de resíduo. O resíduo é formado principalmente por sílica $(94,8 \%)$ que tende a diminuir a retração linear devido ao seu caráter inerte [23]. A retração, ao contrário

Tabela II - Análise granulométrica da argila. [Table II - Granulometric analysis of clay.]

\begin{tabular}{ccc}
\hline \multicolumn{2}{c}{ Fração } \\
\hline Amostra & Areia e silte (\%) & Areia fina, \\
média e grossa (\%) \\
Argila Bruta & 65 & 35 \\
\hline
\end{tabular}


Tabela III - Características dos corpos de prova após a queima com diferentes percentuais de resíduo adicionado. [Table III - Characteristics of the specimens after firing at different percentages of waste added.]

\begin{tabular}{cccc}
\hline Denominação & Resistência à compressão $(\mathrm{MPa})$ & Absorção de água $(\%)$ & Massa específica $\left(\mathrm{g} / \mathrm{cm}^{3}\right)$ \\
\hline T0 & $11,44 \pm 1,70$ & $19,28 \pm 0,57$ & $1,94 \pm 0,15$ \\
T5 & $7,90 \pm 1,29$ & $21,26 \pm 0,59$ & $1,84 \pm 0,03$ \\
T9 & $6,39 \pm 1,13$ & $22,77 \pm 0,74$ & $1,83 \pm 0,0$ \\
T13 & $4,68 \pm 0,90$ & $24,25 \pm 1,03$ & $1,82 \pm 0,01$ \\
T17 & $3,57 \pm 0,52$ & $24,96 \pm 1,22$ & $1,81 \pm 0,01$ \\
\hline
\end{tabular}

Valor médio \pm desvio padrão $(n=5)$

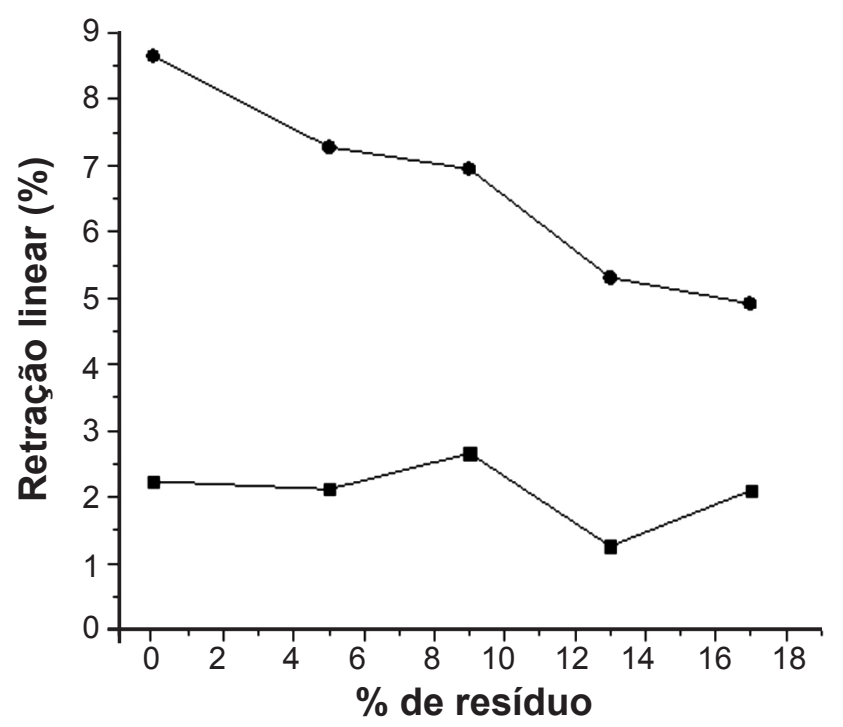

Figura 2: Retração linear das composições, sendo (•) após secagem da cerâmica e $(\bullet)$ após queima da cerâmica.

[Figure 2: Linear shrinkage of the compositions, (-) after drying of ceramics $(\bullet)$ after firing ceramic.]

do que aconteceu com a absorção de umidade, diminuiu na medida em que se acrescentam maiores teores de resíduos. Em um primeiro momento, quanto menor a retração, melhor seria para o processo de produção dos tijolos, principalmente na secagem, pois, os riscos de ocorrerem trincas seriam menores. Para retração não há norma que regularize limites mínimos ou máximos, no entanto, as medidas dos tijolos depois de queimados são padronizadas pelas normas da ABNT. Nesse caso, é essencial determinar o percentual de retração do tijolo para poder adequar o mesmo às medidas normatizadas.

A partir da Fig. 3 pode-se visualizar a presença de partículas com morfologia irregular com cantos angulosos (microscopia b).

A micrografia (a) difere da micrografia (b) por apresentar fragmentos característicos das gemas, sendo que estes resultados estão de acordo com estudos [28] que mencionam a existência de coloração leitosa e a presença de inclusões aciculares em gemas provenientes do sul do Brasil. O fragmento na micrografia (b) apresenta-se problemático na produção de tijolos, pois há prejuízo no sistema de corte, fazendo com que haja a interrupção da produção, devido ao
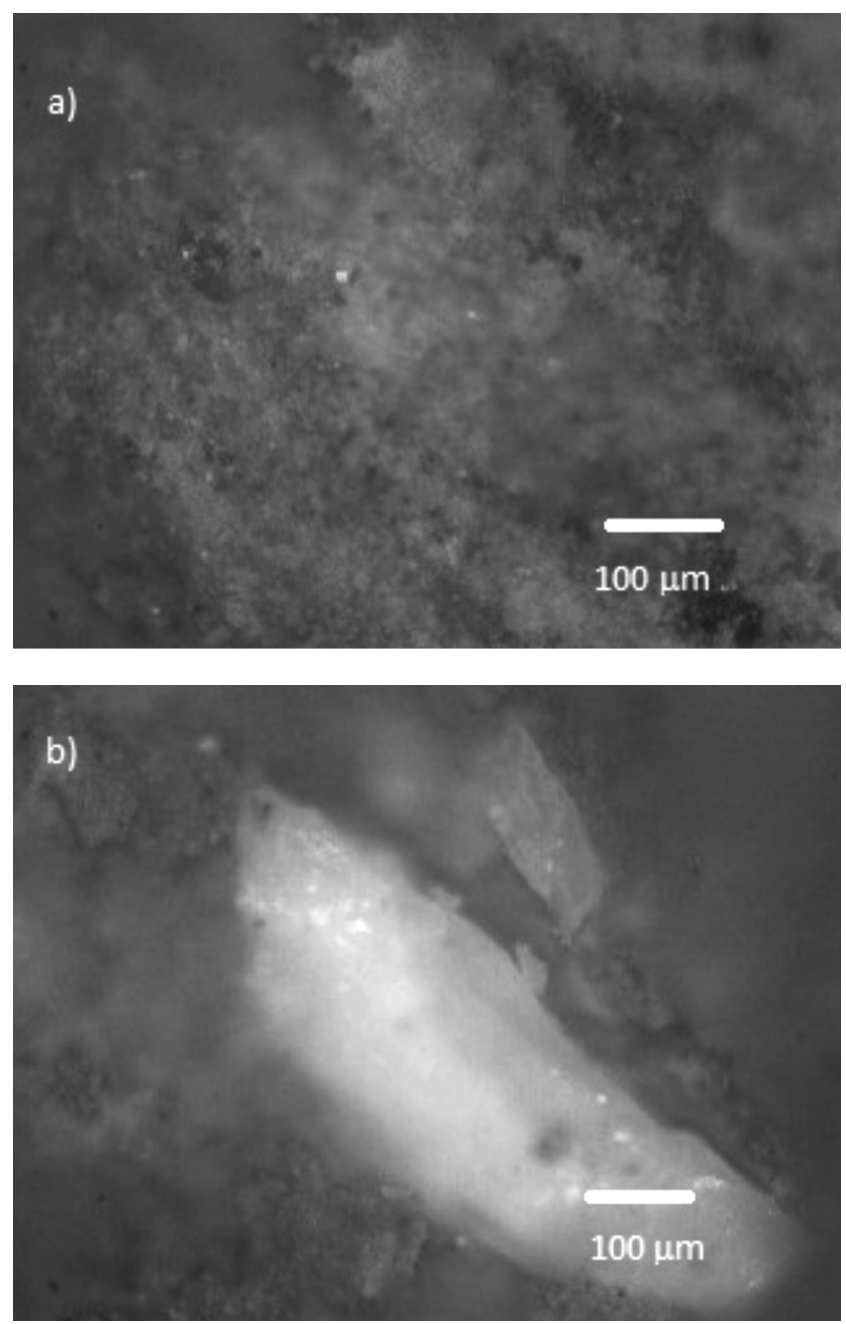

Figura 3: Micrografias dos corpos de prova: (a) sem adição de lodo de gemas; (b) com adição de 5\% de lodo de gemas (aumento de 100x).

[Figure 3: Micrographs of tasting glasses: (a) without addition of sludge bud, (b) with addition of 5\% of sludge bud (100x magnifications).]

rompimento dos fios de aço do cortador. A dimensão destas partículas pode influenciar no aumento da porosidade dos tijolos e conseqüentemente repercutirem no aumento da absorção de água e na diminuição de resistência dos tijolos. Além disso, também pode contribuir no aparecimento de trincas, pois, na região onde a gema está localizada 
apresenta grande porosidade, facilitando a perda de umidade, resultando então, nas rachaduras.

\section{CONCLUSÕES}

Pode-se indicar a incorporação de até $5 \%$ de lodo de gemas à massa cerâmica vermelha. Mesmo que alguns resultados indiquem que seja possível a incorporação de quantidades maiores do resíduo, são necessárias avaliações criteriosas seguindo as normas técnicas vigentes. $\mathrm{O}$ teste de absorção de água mostra que quando adicionadas quantidades superiores a $5 \%$ de resíduo, os resultados ficam fora do parâmetro estabelecido pelas normas técnicas. Existe viabilidade econômica para a incorporação do resíduo pois a empresa produtora, atualmente, o encaminha para descarte. Além disso, outra possibilidade de aproveitamento deste resíduo é nas indústrias produtoras de gemas e jóias, pois trata-se de matéria prima com elevado teor de quartzo (95\%).

\section{AGRADECIMENTOS}

Ao Centro Tecnológico de Gemas e Jóias da UNIVATES, a Caye Pedras Brasil de Teutônia, a Cerâmica Bruxel Ltda. de Arroio do Meio, ao Centro de Tecnologia de Materiais do SENAI de Criciúma-SC, à Escola de Educação Profissional SENAI Nilo Bettanin e ao Laboratório de Cerâmicos LACER/UFRGS.

\section{REFERÊNCIAS}

[1] R. R. Menezes, G. A. Neves, H. C. Ferreira, Rev. Bras. Eng. Agr. Amb. 6, 2 (2002) 303a.

[2] J. B. Silva, D. Hotza, A. M. Segadães, W. Acchar, Cerâmica 51, 320 (2005) 325.

[3] G. C. Xavier, F. Saboya, P. C. A. Maia, J. Alexandre, Cerâmica 55, 333 (2009) 1.

[4] R. R. Menezes, H. S. Ferreira, G. de A. Neves, H. C. Ferreira, Cerâmica 48, 306 (2002) 92.

[5] R. M. Pinheiro, C. M. F. Vieira, R. S. Rodriguez, S. N. Monteiro, Rev. Matéria 13 (2008) 220.

[6] L. C. C. Paixão, H. N. Yoshimura, D. C. R. Espinosa, J. A. S. Tenório, Cerâmica 54, 329 (2008) 63.

[7] E. M. S. Oliveira, J. N. F. Holanda, Cerâmica 54, 330 (2008) 167.

[8] E. M. Bigélli, Utilização de escória de chumbo em massa cerâmica vermelha, Diss. Mestrado, Programa de Pós-Graduação em Engenharia, Universidade Federal do Paraná, Curitiba, PR (2005) 63.

[9] C. M. F. Vieira, S. N. Monteiro, Rev. Matéria 11 (2006) 217.

[10] C. M. F. Vieira, E. T. A. de Souza, S. N. Monteiro, Cerâmica 50, 315 (2004) 254.
[11] C. M. F. Vieira, C. A. C. M. Dias, A. V. Mothé, R. Sánchez, S. N. Monteiro, Cerâmica 53, 328 (2007) 381.

[12] M. C. Borlini, H. F. Sales, C. M. F. Vieira, R. A. Conte, D. G. Pinatti, S. N. Monteiro, Cerâmica 51, 319 (2005) 192. [13] C. M. F. Vieira, S. C. Intorne, F. Vernilli Jr, S. N. Monteiro, Rev. Matéria 12 (2007) 269b.

[14] IBGM, Manual Técnico de Gemas / IBGM, DNPM, 4a Ed., Brasília, DF (2009).

[15] BRASIL, Ministério do Desenvolvimento, Indústria e Comércio Exterior - MDIC, Políticas e ações para a cadeia produtiva de gemas e jóias, Brasília, DF (2005).

[16] C. C. Ribeiro, J. D. da S. Pinto, T. Starling, Materiais de construção civil, $2^{\text {a }}$ Ed., UFMG, Belo Horizonte, MG (2002) 102p.

[17] C. L. Langhanz, Análise do setor industrial de cerâmica vermelha no $R S$, Anais $35^{\circ}$ Cong. Bras. Ceram., Belo Horizonte, 2 (1991) 819-826.

[18] G. M. Bustamante, J. C. Bressiani, Ceram. Ind. 5 (2000) 31.

[19] SINDICER, Diagnóstico da Indústria da Cerâmica Vermelha do Estado do Rio Grande do Sul, Rel. Pq., SENAI, FIERGS, Porto Alegre, RS (2008) 88p.

[20] Associação Brasileira de Normas Técnicas - ABNT NBR 10004: Resíduos de minerais não-metálicos - Codificação de alguns resíduos classificados como não perigosos, Rio de Janeiro, RJ (2004).

[21] Associação Brasileira de Normas Técnicas - ABNT NBR 7181: Determinação da análise granulométrica de solos, Rio de Janeiro, RJ (1984).

[22] Associação Brasileira de Normas Técnicas - ABNT NBR 15270-1: Componentes cerâmicos Parte 1: Blocos cerâmicos para alvenaria de vedação - Terminologia e requisitos, Rio de Janeiro, RJ (2005).

[23] L. F. T. Queiroz, S. N. Monteiro, C. M. F. Vieira, Cerâmica 56, 339 (2010) 279.

[24] Associação Brasileira de Normas Técnicas - ABNT NBR 15270-2: Componentes cerâmicos Parte 2: Blocos cerâmicos para alvenaria estrutural - Terminologia e requisitos, Rio de Janeiro, RJ (2005).

[25] Associação Brasileira de Normas Técnicas - ABNT NBR 15270-3: Componentes cerâmicos Parte 3: Blocos cerâmicos para alvenaria estrutural e de vedação-Métodos de ensaio, Rio de Janeiro, RJ (2005).

[26] M. M. Fernandes, Mecânica dos Solos - Conceitos e principios fundamentais, Vol. 1, FEUP Ed., Porto, Portugal (2008).

[27] F. M. S. Ramos, O. T. Kaminata, C. R. G. Tavares, C. T. Benatti, M. Capelasso, B. D. Innocenti, Cerâmica 55, 336 (2009) 408.

[28] L. C. Duarte, P. L. Juchem, G. M. Pulz, T. M. M. de Brum, N. Chodur, A. Liccardo, A. C. Fischer, R. B. Acauan, Pesq. Geoci. 30, 2 (2003) 3.

(Rec. 08/02/2011, Rev. 30/05/2011, Ac. 10/06/2011) 